\title{
Reducing Preterm Birth in lowa with Centering Pregnancy
}

\author{
Laura Dellos, ARNP, $\mathrm{CNM}^{1}$ and Kimberly K. Marshall, MBA ${ }^{1}$
}

Key Words: preterm birth, prenatal care, pregnancy, pregnancy outcome, midwifery

\begin{abstract}
Centering Pregnancy $(\mathrm{CP})$ is a model of group care that integrates the three major components of care: Health assessment, education, and support, into a unified program within a group setting. Centering model's evidence showing statistically significant improvements in 1) birth weights of infants born prematurely (gain of 400 gm), 2) a lengthening in the gestation of the babies born prematurely (34 weeks group vs. 32 weeks individual), 3) increased rates of breastfeeding, 4) higher satisfaction with care, and 5) feelings of increased preparation and knowledge. This article describes current efforts at the University of lowa Hospitals and Clinics (UIHC) to implement the CP program.
\end{abstract}

at least one $\mathrm{CP}$ program. Centering Pregnancy is a model of group care that integrates the three major components of care: health assessment, education, and support, into a unified program within a group setting. This "definition" does not always sufficiently explain this innovative approach and for those unfamiliar with $\mathrm{CP}$ it is important to know that CP IS NOT a "class" that is offered in addition to traditional prenatal care. Instead,

${ }^{1}$ The Department of Obstetrics and Gynecology, The Carver College of Medicine, The University of lowa, lowa City, Iowa, USA

Centering Pregnancy is a dynamic process. Women actively participate in their care and are supported by group interactions to make healthy choices. Facilitators are energized and encouraged to use creative approaches to convey the content of each session.

\section{Introduction}

Centering Pregnancy (CP) was developed by Sharon Schindler Rising, CNM, in the early 1990s. In the past decade the model has been implemented throughout the U.S. with strong funding support by the March of Dimes. Every state bordering lowa has

\section{Centering Pregnancy IS:}

\section{A Facilitated Group Process:}

Eight to twelve women comprise the group and seating is always arranged in a circle. While there is an over-all plan

Please cite this paper as: Dellos L, Marshall KK. Reducing preterm birth in lowa with Centering Pregnancy. Proc Obstet Gynecol. 2011 November;2(2):Article 11 [ 5 p.]. Available from: http://ir.uiowa.edu/pog/. Free full text article.

Corresponding author: Laura Dellos. Department of Obstetrics and Gynecology, University of lowa, 31150 PFP, 200 Hawkins Drive, lowa City, IA 52242. laura-dellos@uiowa.edu.

This is an Open Access article distributed under the terms of the Creative Commons Attribution 3.0 Unported License (http://creativecommons.org/licenses/by/3.0), which permits unrestricted use, distribution, and reproduction in any medium, provided the original work is properly cited 
for each session, the structure is flexible to allow for particular needs of the group. An emphasis is made on building a sense of community within the group, so the composition of the group is stable.

\section{Prenatal Care:}

Individual assessments are done at every group session and occur privately within the group space. Thus, CP meets all required components for a prenatal visit and is billable to all payers including Medicaid. Women continue to have the same steps in initiating prenatal care: an individual new patient visit is scheduled and risk factors are identified through a complete medical history reviewed by an RN, CNM or physician. A physical exam may also be done at this visit. Information about CP is shared by clinic staff and/or her providers; she may then elect to participate in CP for the majority of her care. Women with similar due dates begin meeting at 12-16 weeks gestation. Group meetings occur monthly until 2832 weeks and then every two weeks. During the last month of pregnancy patients alternate weekly appointments with their primary $\mathrm{OB}$ provider and group sessions. Meeting times are set so that upon entry to group care, a woman knows the dates and times for all group sessions.

\section{Evidence Based:}

By taking women out of lines and waiting rooms, CP provides 90 minutes of quality time every session with the same two facilitators. In traditional care, women may spend 5 to 15 minutes with a provider at each encounter; often after a considerable wait. In a busy clinic, the provider may have little time for providing detailed information. In contrast, CP offers comprehensive education on risk reduction and healthy choices. This key difference may play an important role in the Centering model's evidence showing statistically significant improvements in 1) birth weights of infants born prematurely (gain of $400 \mathrm{gm}$ ), 2) a lengthening in the gestation of the babies born prematurely (34 weeks group vs. 32 weeks individual), 3) increased rates of breastfeeding, 4) higher satisfaction with care, and 5) feelings of increased preparation and knowledge. A secondary benefit of $\mathrm{CP}$ is the potential to provide or enhance preconception health education for subsequent pregnancies of participants through knowledge gained about risk reduction in the current pregnancy.

Research on Centering shows that per 1000 women in group care, 40 preterm births could be averted! 
Goals of Centering Pregnancy at UIHC

The desired impact of this project is the same for the Centering Healthcare Institute $(\mathrm{CHI})$ and $\mathrm{UIHC}$ : To improve the overall health outcomes of mothers and babies. Disparities in outcomes do exist in lowa and preterm birth has increased over the past decade. Centering Pregnancy primarily addresses the March of Dimes funding goal of enhancing care through the Centering model, which provides risk reduction education and/or services that will help to reduce disparities in premature birth in lowa through an evidence-based and measurable model of prenatal care.

\begin{tabular}{|llll|}
\hline $\begin{array}{l}\text { DATA FOR } \\
\text { IOWA }\end{array}$ & 1996 & 2006 & $\begin{array}{l}2010 \text { US } \\
\text { Objective }\end{array}$ \\
\hline Preterm & $\mathbf{1 0 \%}$ & $\mathbf{1 1 . 6 \%}$ & $\mathbf{7 . 6 \%}$ \\
\hline $\begin{array}{l}\text { Low } \\
\text { birthweight }\end{array}$ & $\mathbf{6 . 4 \%}$ & $\mathbf{6 . 9 \%}$ & $\mathbf{5 . 0 \%}$ \\
\hline
\end{tabular}

According to the March of Dimes PeriStats for lowa, there were 4,730 preterm births in lowa in 2007; this reflected an 11\% increase from 1997. In 2001 the US National Vital Statistics reports the average cost of an infant born between 32 and 37 weeks gestation was $\$ 34,000$. In addition to cost, families of infants needing intensive care experience a severe emotional impact. By extending the length of the pregnancy from 32 to 34 weeks, as the evidence has shown with the CP Model, this economic and emotional burden may be greatly reduced.

\begin{tabular}{|l|l|l|l|}
\hline $\begin{array}{l}\text { lowa Birth } \\
\text { Events 2003 }\end{array}$ & Hispanic & Black & White \\
\hline $\begin{array}{l}\text { Births to single } \\
\text { mothers }\end{array}$ & $43 \%$ & $75 \%$ & $29 \%$ \\
\hline $\begin{array}{l}\text { Mothers Under } \\
\text { Age 20 }\end{array}$ & $15 \%$ & $22 \%$ & $8 \%$ \\
\hline $\begin{array}{l}\text { Low Birth } \\
\text { Weight (<2500 } \\
\text { grams) }\end{array}$ & $16 \%$ & $13 \%$ & $6 \%$ \\
\hline
\end{tabular}

When compared to the U.S. as a whole, lowa is less diverse than other states. However, this data is changing as lowa continues to experience a shift in demographics. According to the lowa Center for Health Disparities, rapid ethnic diversifiation is occuring in the state resulting in higher birth rates among ethnic minorities in lowa. Racial disparities in the preterm birth rate in the U.S. and lowa are profound and unless programs are enacted that target reducing these disparities, the rate of preterm birth will continue to rise.

At UIHC, in order to encompass multiple socioecomnomic groups, CP care will be offered to all English speaking women entering care at the UI Women's Health Center. This CP project will primarily serve women in Johnson County, although UIHC draws women from the surrounding five county area. Johnson County has seen a doubling of high-risk populations in the last ten years, including black and Hispanic populations, which is attributed to relocation of families from urban areas as well as an increase in refugee 
populations. The experience at $\mathrm{UI}$ Women's Health Center is that Hispanic women often enter into care later in pregnancy, likely due to social and economic barriers to care. Our first offering of a Spanish language group has not filled at the time of this submission. A goal for 2012 is to collect more data on this group and strategize how to offer this model to this population of women at UIHC. A future goal includes establishing the model in Washington County in hopes of serving Spanish speaking women in the surrounding areas.

\section{Implementing CP at UIHC}

The Centering Health Institute $(\mathrm{CHI})$ has a two year implementation plan designed to successfully launch the model. The plan includes a consultant for assistance with system redesign, training of facilitators, recruitment of clients, group start-up, and a site evaluation. March of Dimes funding for 2011 allowed for the first phase of the implementation plan at UIHC. Specifically, a key requirement for this model is physical space, and UIHC has remodeled a room within the Women's Health Center that will accommodate the creative and interactive methods that are central to the CP program. This approximately $\$ 3500$ renovation was made possible by the Ambulatory Care Division with strong support of administration. The Women's Health Center is supplying the blood pressure monitor, scale and doppler.
An introductory meeting for the Implementation Team was held October 2010. This team includes key personnel from scheduling, nursing management, and faculty providers. A Centering Project Assistant, Kimberly Marshall, was hired August 2011. A Facilitator Training Workshop in August 2011 was attended by 18 participants, including eight faculty providers. Furthermore, OB/GYN residents will have the opportunity to train and participate in the model. The goal is that these providers will be able to implement $\mathrm{CP}$ in future practices after completion of their residency program, thus helping to fulfill the mission of the residency training program, and supporting UIHC's role as an educational resource for the state.

Two groups have been organized to date with a total enrollment of 17 patients. To facilitate patient education, CP participants receive a notebook at the first session to bring to each group meeting. These have been provided for the first 50 group participants through the March of Dimes grant. UIHC Marketing has generously provided some materials including website and pamphlet design.

\section{Benchmarks for Success}

Ongoing program evaluation will occur and is required for gaining site approval by $\mathrm{CHI}$ as well as continued funding from the March of Dimes. Our benchmarks for success are to 1) decrease preterm birth incidence among Centering participants to below the baseline state average of $11.6 \% ; 2$ ) 
demonstrate a change in maternal behavior as evidenced by appropriate maternal weight gain during pregnancy; and 3) to improve participant preparedness for birth and parenting. We strongly believe that the investment in a model of care that could significantly reduce preterm birth in lowa, as well as positively impact other key indicators, is well worth attention and support.

\section{About the Authors:}

Project Manager. Laura Dellos, ARNP, CNM received her MSN from the University of California-San-Francisco and has 20 years of experience providing prenatal care in rural, urban and academic settings. She has previous experience with the $\mathrm{CP}$ model and attended a training workshop in August 2010. Additionally, she has developed group care options for new obstetrical patient visits in two previous practices.

Project Assistant. Kimberly Marshall has a BA in Psychology and an MBA with a specialty in healthcare management. She has been an Academic Advisor at The University of Phoenix and an Office Coordinator at the American Diabetes Association. These positions gave her a great deal of experience managing groups of people and data. Now, back at the University of lowa Hospitals and Clinics in the Women's Health Center as a clerk, she has reception and scheduling experience offering eight years experience in the field of women's healthcare. 